\title{
Increase of organic carbon burial response to mangrove expansion in the Nanliu River estuary, South China Sea
}

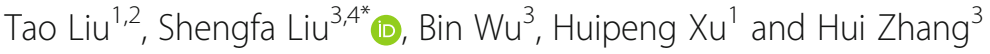

\begin{abstract}
Due to high productivity, periodic submersion, and rapid sedimentation rate, mangroves are important carbon sinks in tropical-subtropical coastal zones. Mangrove expansion can significantly enhance burial carbon storage in coastal zones and has been reported in many subtropical regions due to climate change in recent years. To better understand the response of carbon storage to climate change in subtropical-tropical coastal zones, it is necessary to estimate the change in burial organic carbon (OC) storage in mangroves undergoing expansion. In the Nanliu River estuary of South China, the total mangrove area has increased from 72 to 622 ha in recent decades. Based on a sedimentology study combined with historical satellite images analysis, the accumulation rate of burial $\mathrm{OC}$ in these mangroves is estimated to be $400-500 \mathrm{~g} \cdot \mathrm{m}^{-2} \cdot \mathrm{y}^{-1}$, of which the part imported to the stratigraphy beneath the mangrove deposit layer is approximately $130 \mathrm{~g} \cdot \mathrm{m}^{-2} \cdot \mathrm{y}^{-1}$. Globally, the reported OC accumulation rate is linearly correlated to the accretion rate in mangroves. The accumulation rate of mangrove burial OC estimated in this study is significantly higher than the corresponding value on this fitted curve, indicating that the OC accumulation rates may be underestimated in such mangroves because the $\mathrm{OC}$ imported to the lower root layer has been not been taken into account. Based on the estimated OC accumulation rate and the time-series data of the mangrove area, the increase in burial OC storage in the mangroves of the Nanliu River estuary from 1988 to 2018 is estimated at more than $35 \mathrm{Gg}$. This study provides an example of estimating soil OC storage increase in expanding mangroves, which can help us better understand the response of coastal carbon pool to climate change.
\end{abstract}

Keywords: Climate change, Mangrove, Accumulation rate, Organic carbon burial, South China Sea

\section{Introduction}

Mangrove sediment can sequester a large amount of organic carbon $(\mathrm{OC})$ due to the high primary productivity, rapid accretion rate, and water-logged anaerobic soil environment of mangroves (Mcleod et al., 2011; Alongi, 2014; Jardine and Siikamäki, 2014). Although mangroves only cover $0.5 \%$ of the global coastal area, they account for $10-15 \%$ of coastal sediment OC storage (Donato et al., 2011; Ezcurra et al., 2016). The total mangrove area of the

\footnotetext{
* Correspondence: liushengfa@fio.org.cn

${ }^{3}$ Key Laboratory of Marine Geology and Metallogeny, First Institute of Oceanography, Ministry of Natural Resources, Qingdao 266061, China ${ }^{4}$ Laboratory for Marine Geology, Qingdao National Laboratory for Marine Science and Technology, Qingdao 266061, China

Full list of author information is available at the end of the article
}

world has decreased sharply in the past century mainly due to human-induced land-use change (Giri et al., 2011). However, in recent decades, mangroves in many subtropical regions are reported to have expanded due to climate change (Pérez et al., 2017; Saintilan et al., 2014a; Cavanaugh et al., 2014; Liu et al., 2017).

To estimate the increase in carbon storage by mangroves, the increase in burial $\mathrm{OC}$ storage due to mangrove expansion should be determined. In the Nanliu River estuary of South China, mangroves have replaced most of the salt marsh and have expanded into bare flat land due to increases in rainfall. This has resulted in a significant increase in the mangrove area from 73 ha in 1988 to 622 ha in 2018. The aim of this study is to determine the burial OC
Springer Open (c) The Author(s). 2020 Open Access This article is licensed under a Creative Commons Attribution 4.0 International License, which permits use, sharing, adaptation, distribution and reproduction in any medium or format, as long as you give appropriate credit to the original author(s) and the source, provide a link to the Creative Commons licence, and indicate if changes were made. The images or other third party material in this article are included in the article's Creative Commons licence, unless indicated otherwise in a credit line to the material. If material is not included in the article's Creative Commons licence and your intended use is not permitted by statutory regulation or exceeds the permitted use, you will need to obtain permission directly from the copyright holder. To view a copy of this licence, visit http://creativecommons.org/licenses/by/4.0/. 
accumulation rate and the increase in burial OC storage due to the expansion of mangroves in this area. Based on divisions of the sedimentary facies in two sediment cores, the amount of burial $\mathrm{OC}$ related to the presence of mangroves was calculated using the depth profile of OC density. Using the age of mangrove plants determined by historical satellite image analysis, the accumulation rate of burial $\mathrm{OC}$ in mangroves was calculated. Furthermore, using the $\mathrm{OC}$ accumulation rate and the time series of the mangrove area, the increase in burial OC storage from 1987 to 2018 was estimated. To estimate the storage of OC related to mangrove forests, it is necessary to identify the mangrove deposit layer in stratigraphy. By studying the $\mathrm{OC}$ content, sand content, and plant residual in sediment cores, three kinds of sedimentary facies can be identified.

\section{Study area and methods}

This study was conducted in the Nanliu River estuary along the northern coast of the South China Sea (Fig. 1). The study area is influenced by a subtropical monsoon climate. During the past 60 years, the average annual temperature was $22^{\circ} \mathrm{C}$ and the average annual rainfall was approximately $1600 \mathrm{~mm}$. With an average tidal range of $2.5 \mathrm{~m}$, the diurnal tide dominates in this region. Large mangroves grow on the upper tidal flat of the river mouths. The vegetation mainly consists of Aegiceras corniculatum, with a small number of Kandelia candel as well as Sonneratia apetala. The plant height is in the range of $1-4 \mathrm{~m}$. An increase in river discharge during this period is thought to have triggered the rapid expansion of mangroves, a significant expansion of mangroves in Nanliu River estuary during past decades could be found in Fig. 2.

In 2017 , two sediment cores $(100 \mathrm{~cm}$ in length and 5 $\mathrm{cm}$ in diameter) were collected from a mangrove forest off the mouth of the Nandongjiang River (a distributary of the Nanliu River). Core C3 was collected in a relatively older mangrove patch ( $20-30$ years) while core C7 was collected from a young mangrove patch of approximately 10 years (as inferred using satellite remote sensing images). The sediment cores were sectioned in $2 \mathrm{~cm}$ intervals. Then, once the fresh roots were removed, each subsection was analysed for dry bulk density, total organic carbon (TOC), and grain size in a laboratory.

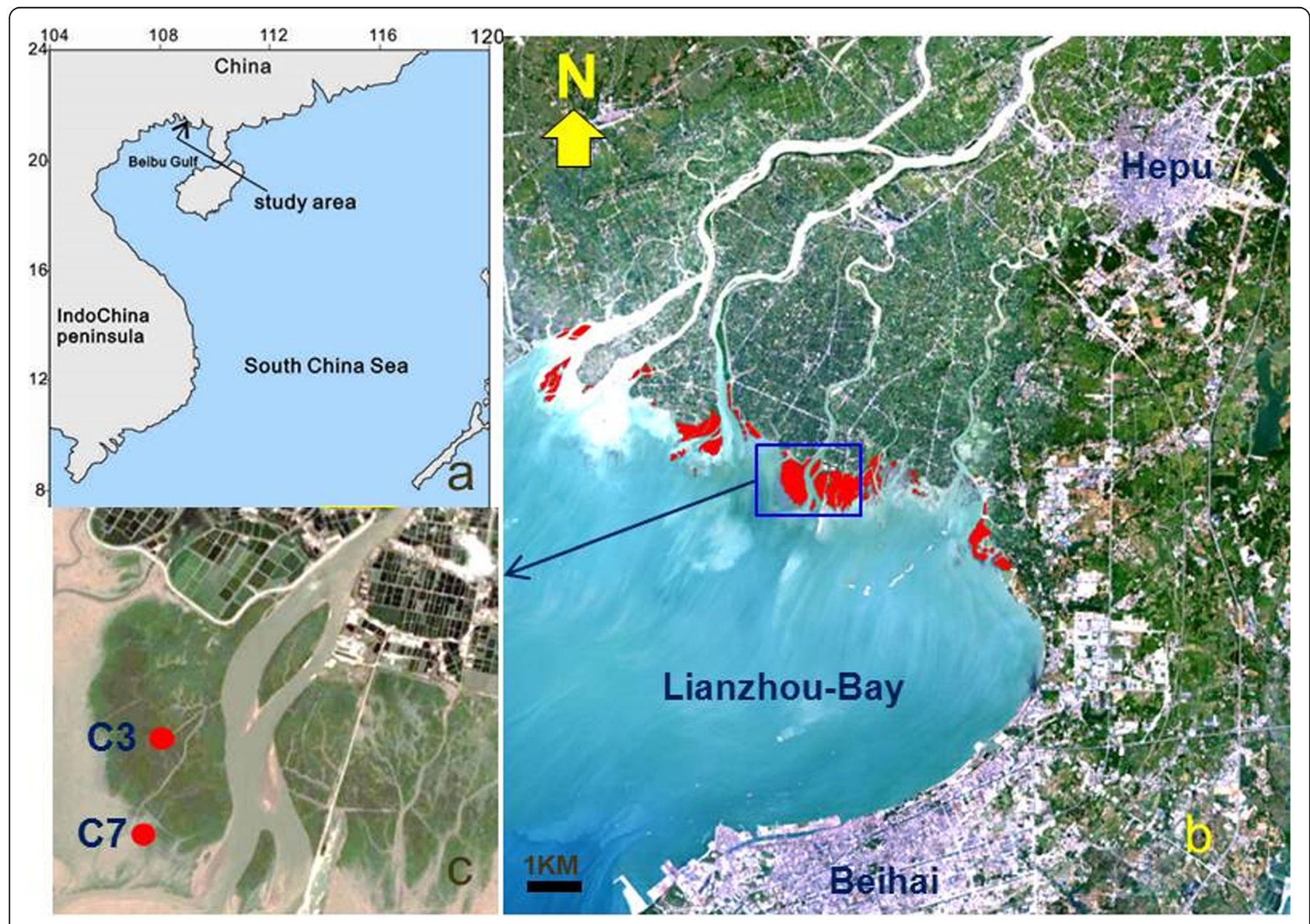

Fig. 1 Study area (a)and the spatial distribution of mangroves off Nanliu River mouth (b), mangroves are marked by the red area, the position of sediment cores is marked too $(\mathbf{c})$ 


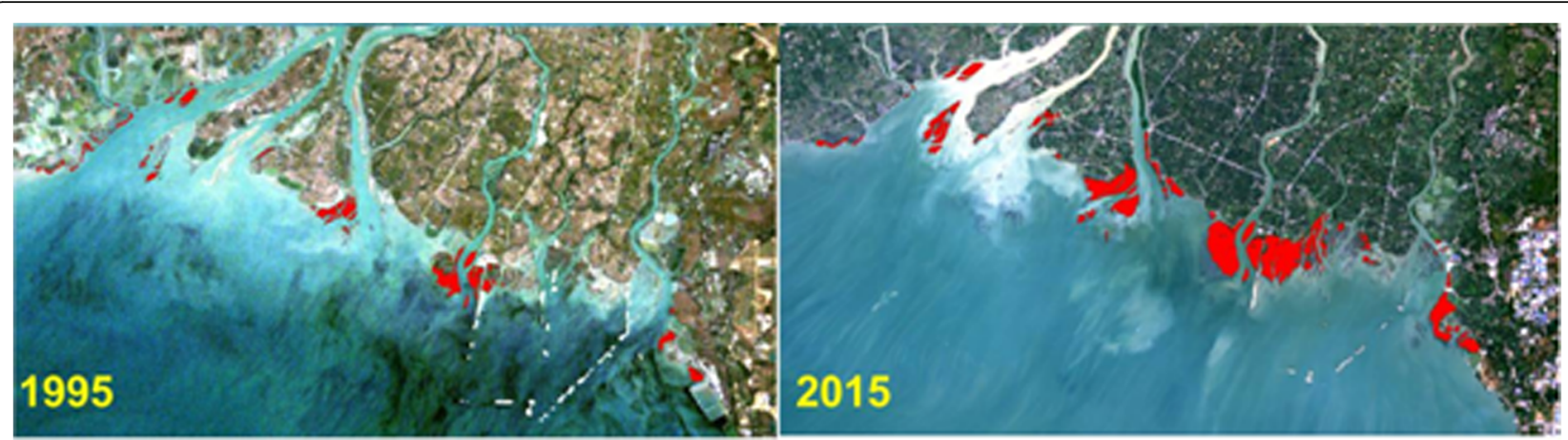

Fig. 2 The significant expansion of mangroves in Nanliu River estuary during past decades

We utilised a mini ring-knife and a drying oven to determine the dry bulk densities. TOC was measured with a Shimadzu SSM-5000A organic carbon analyser. For sediment grain size analysis, we used a MasterSizer-3000 laser particle size analyser made by the Malvern Company. Firstly, calcareous clastic and organic matter were removed using $5 \% \mathrm{HCl}$ and $10 \% \mathrm{H}_{2} \mathrm{O}_{2}$ solution, respectively. Secondly, $6 \%\left(\mathrm{NaPO}_{3}\right)_{6}$ solution was added as a dispersing agent while the solution was stirred with a glass rod. Thirdly, the sample was added to the laser particle size meter for particle size measurement. Finally, the excess ${ }^{210} \mathrm{~Pb}$ radioactivity of the sediment samples was detected by a $\alpha$-multichannel spectrometer in the State Key Lab of Lake Sciences of China.

\section{Results}

\subsection{Mangrove deposit layer identification in stratigraphy}

In core C3, as the depth increased, deposits of mangrove, salt marsh, and bare flat sediment emerged in turn (Fig. 3). The mangrove deposit (0-22 cm layer) was characterised by high OC content (3-4\%) and stable low sand content (approximately 20\%). Residual mangrove litter can also be found in this layer. The salt marsh deposit (depth range $22-46 \mathrm{~cm}$ ) was characterised by relatively high $\mathrm{OC}$ content $(2-3 \%)$ and fluctuating sand content (15-40\%). The residual of salt marsh plant petioles can also be found in this layer. The bare flat sediment deposit constitutes the layer below $46 \mathrm{~cm}$ and is characterised by low OC content (1-2\%) and high sand content $(40-60 \%)$. In core C7, collected in young mangroves which colonised bare flat sediment after 2005 , the mangrove deposit layer directly overlays the bare flat deposit. Here, the bare flat deposit is only 10 $\mathrm{cm}$ in thickness.

\subsection{Age of mangrove plants and accretion rate in mangroves}

To estimate the accumulation rate of $\mathrm{OC}$ in mangroves, it is necessary to determine the age of the mangroves. In this study, we estimated the age of mangrove plants based on historical satellite images (Fig. 4), according to which we can judge that the mangrove colonising the site where core C3 was taken ('C3 site') in 1992 or 1993. The mangrove plants at this site were approximately 24 years old in 2017. Given that the thickness of the mangrove deposit layer was $22 \mathrm{~cm}$ (Fig. 3), the accretion rate in the mangroves of this site is thus around $9 \mathrm{~mm} / \mathrm{a}$. Historical satellite images show that the C7 site was located just at the margin of the mangrove in 2005. At the end of 2009, the mangrove patch of this site was very clear, indicating the adjacent canopies have been in full touch. This needs more than 3 years in this area. The mangrove colonised there most likely during 2005-2007. The age of the mangrove plants at the $\mathrm{C} 7$ site was no more than 12 years in 2017. Given the thickness of the mangrove deposit layer at this site was $12 \mathrm{~cm}$ (Fig. 3), the accretion rate in the mangrove is therefore estimated at more than $10 \mathrm{~mm} / \mathrm{a}$.

In addition to the analysis based on historical satellite images, we also calculated the accretion rate using the excess $\mathrm{Pb}^{210}$ radioactivity in core $\mathrm{C} 3$. As shown in Fig. 5, except for some abnormal data, excess $\mathrm{Pb}^{210}$ radioactivity in the sediment declined exponentially with depth. Using the CS-CF modal, the accretion rate was calculated at $9.1 \mathrm{~mm} / \mathrm{a}$ in the mangrove deposit layer and 11 $\mathrm{mm} / \mathrm{y}$ in the salt marsh deposit layer. The mangrove is thus estimated to be 22 years old. The accretion rate of the mangrove deposit layer calculated by the $\mathrm{Pb}^{210}$ method is almost the same as that determined using historical satellite images analysis, indicating the validity of historical satellite images analysis in estimating the age of young mangroves.

\subsection{Accumulation rate of burial $\mathrm{OC}$ in mangroves}

Based on the division of sedimentary facies, the amount of OC buried in the mangrove deposit layer and the OC imported to the lower layer can be respectively calculated. At the position of core C7, the burial OC stored in the mangrove deposit layer was calculated to be $4436 \mathrm{~g}$ 


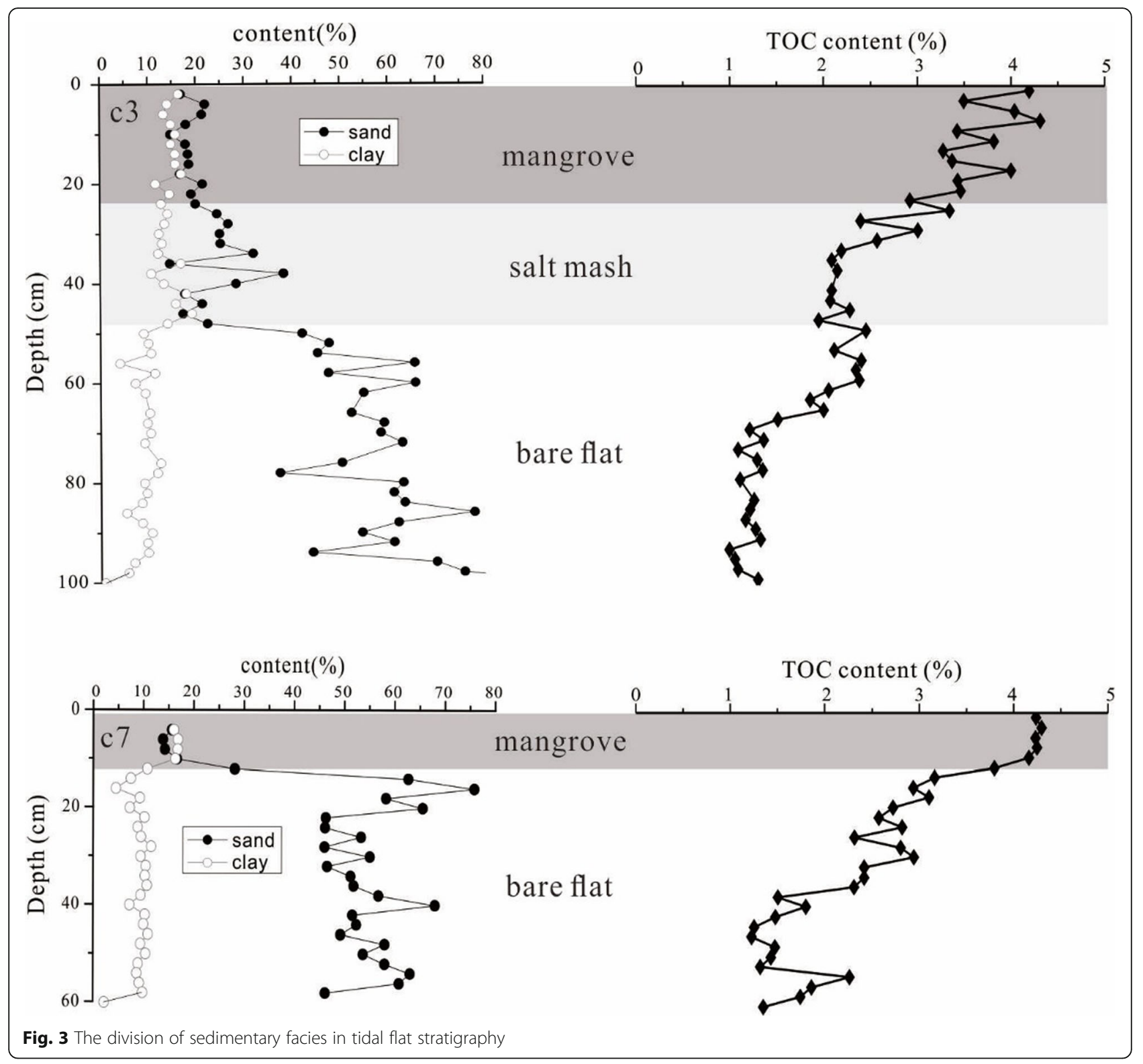

per square meter (Fig. 6a, Table 1). In the bare flat deposit layer below $40 \mathrm{~cm}$, OC density is stable and was approximately $0.022 \mathrm{~g}^{\cdot} \mathrm{cm}^{-3}$ on average. In the upper part of the bare flat deposit layer $(12-40 \mathrm{~cm})$, the OC imported by mangrove roots resulted in an abrupt increase in OC density. The amount of OC per square meter sourced from mangrove roots in this layer is thus determined by subtracting the background OC $(5520 \mathrm{~g})$ from the total OC $(7074 \mathrm{~g})$ and is approximately $1554 \mathrm{~g}$. At this site, the total burial OC related to mangroves is thus $5990 \mathrm{~g}$. Given that the mangrove age at this site was around 12 years at the time of core extraction, the total accumulation rate of burial $\mathrm{OC}$ related to mangroves is around $500 \mathrm{~g} \cdot \mathrm{m}^{-2} \cdot \mathrm{y}^{-1}$, in which the accumulation rate of $\mathrm{OC}$ imported to the lower layer is estimated at $130 \mathrm{~g} \cdot \mathrm{m}^{-2} \cdot \mathrm{y}^{-1}$.

At the position of core $\mathrm{C} 3$, the amount of burial $\mathrm{OC}$ per square meter in the mangrove deposit layer is calculated to be $6498 \mathrm{~g}$. The amount of OC storage by mangrove roots cannot be determined because of its mixing with the $\mathrm{OC}$ from the salt marsh (Fig. 6b). However, we can estimate the OC imported to the lower layer using the data of core C7. Given that the age of the mangrove at this site is around 24 years, the OC imported to the lower layer is estimated to be $3120 \mathrm{~g} \cdot \mathrm{m}^{2}$. Using this data, the total OC related to mangroves and the total $\mathrm{OC}$ related to the salt marsh are determined as $9618 \mathrm{~g} \cdot \mathrm{m}^{-2}$ and $5655 \mathrm{~g} \cdot \mathrm{m}^{-2}$, respectively. 


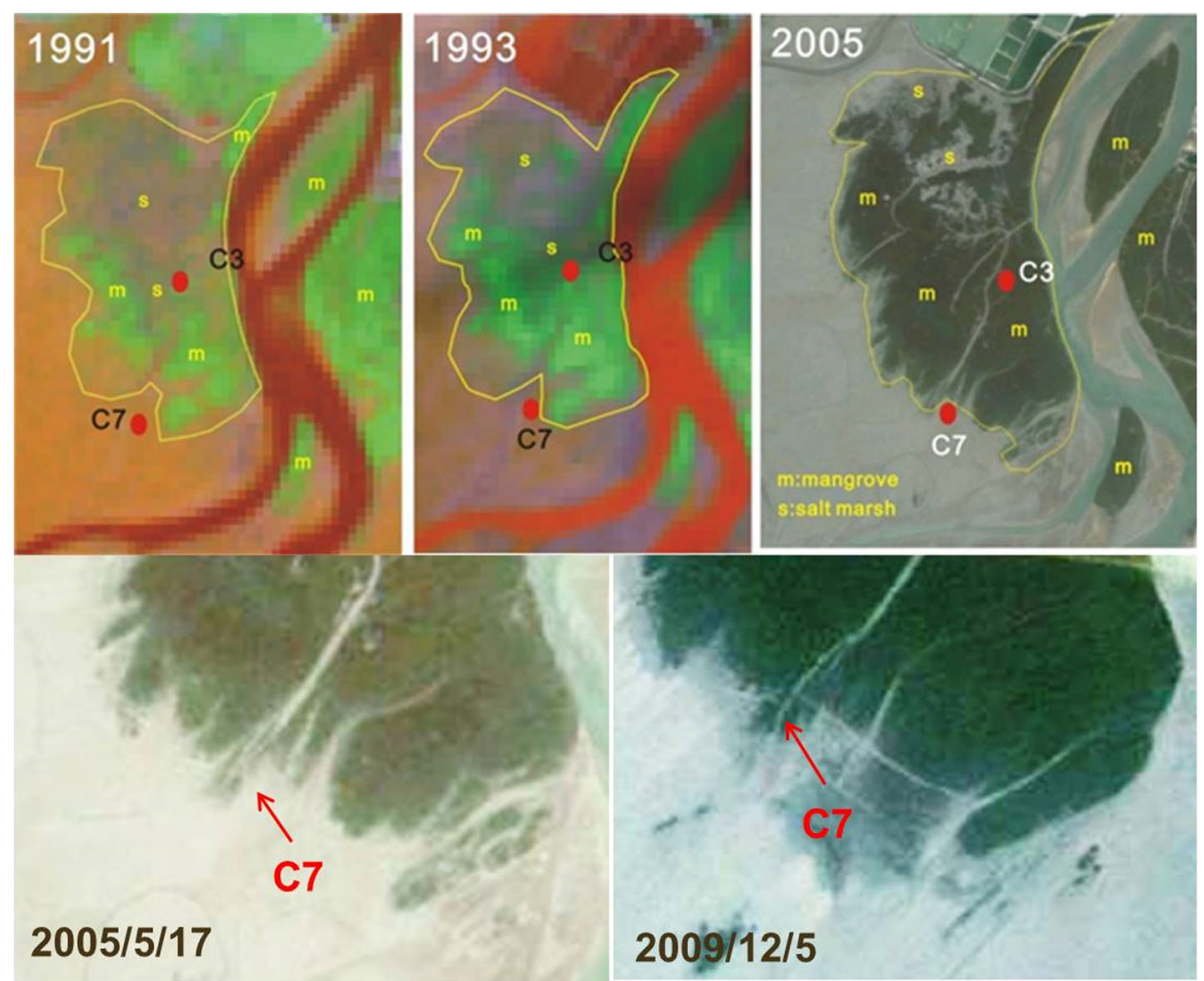

Fig. 4 Position of sediment cores and the spatial distribution of mangrove and salt marsh in satellite images (from landsate and Google earth)

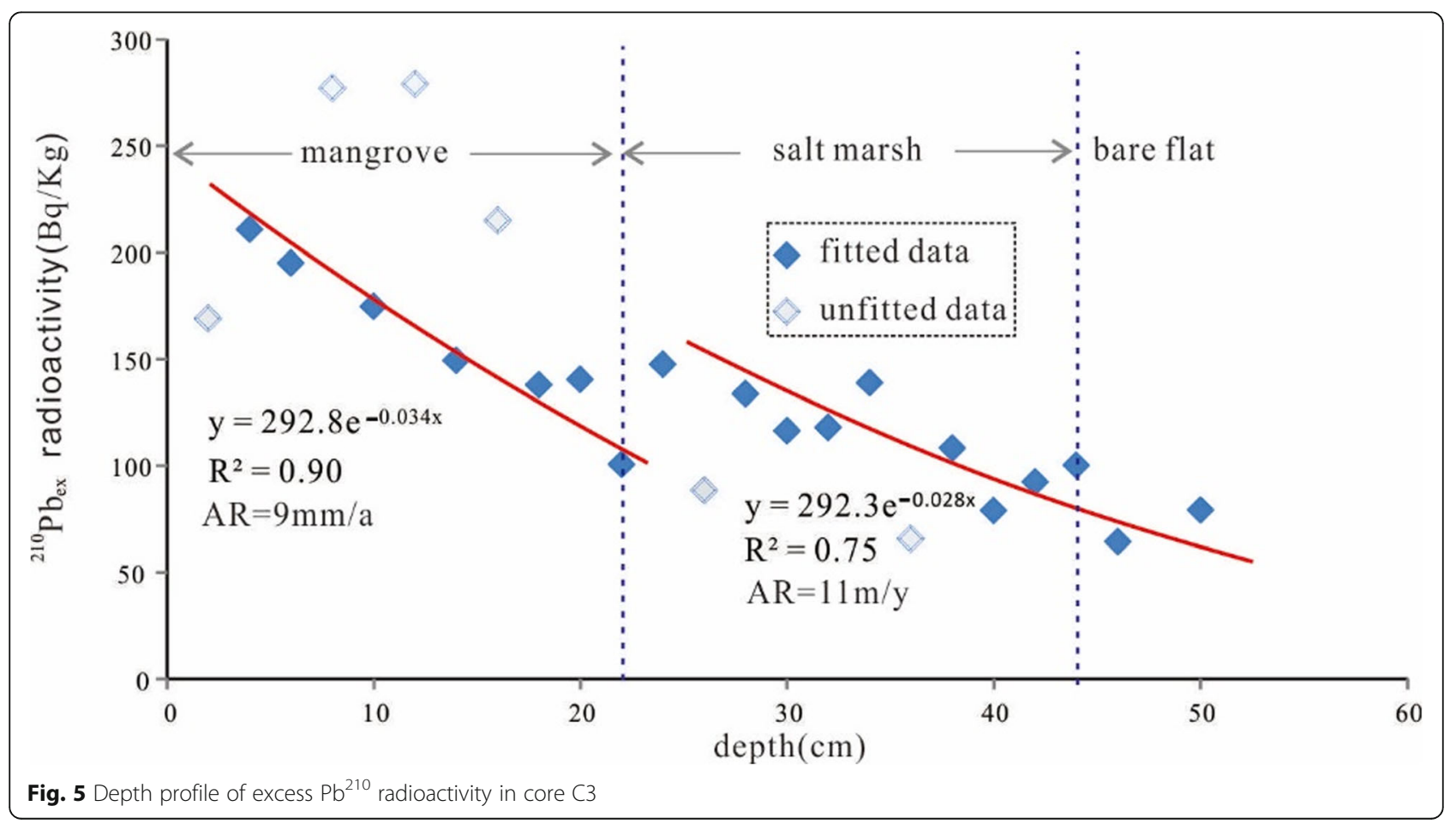




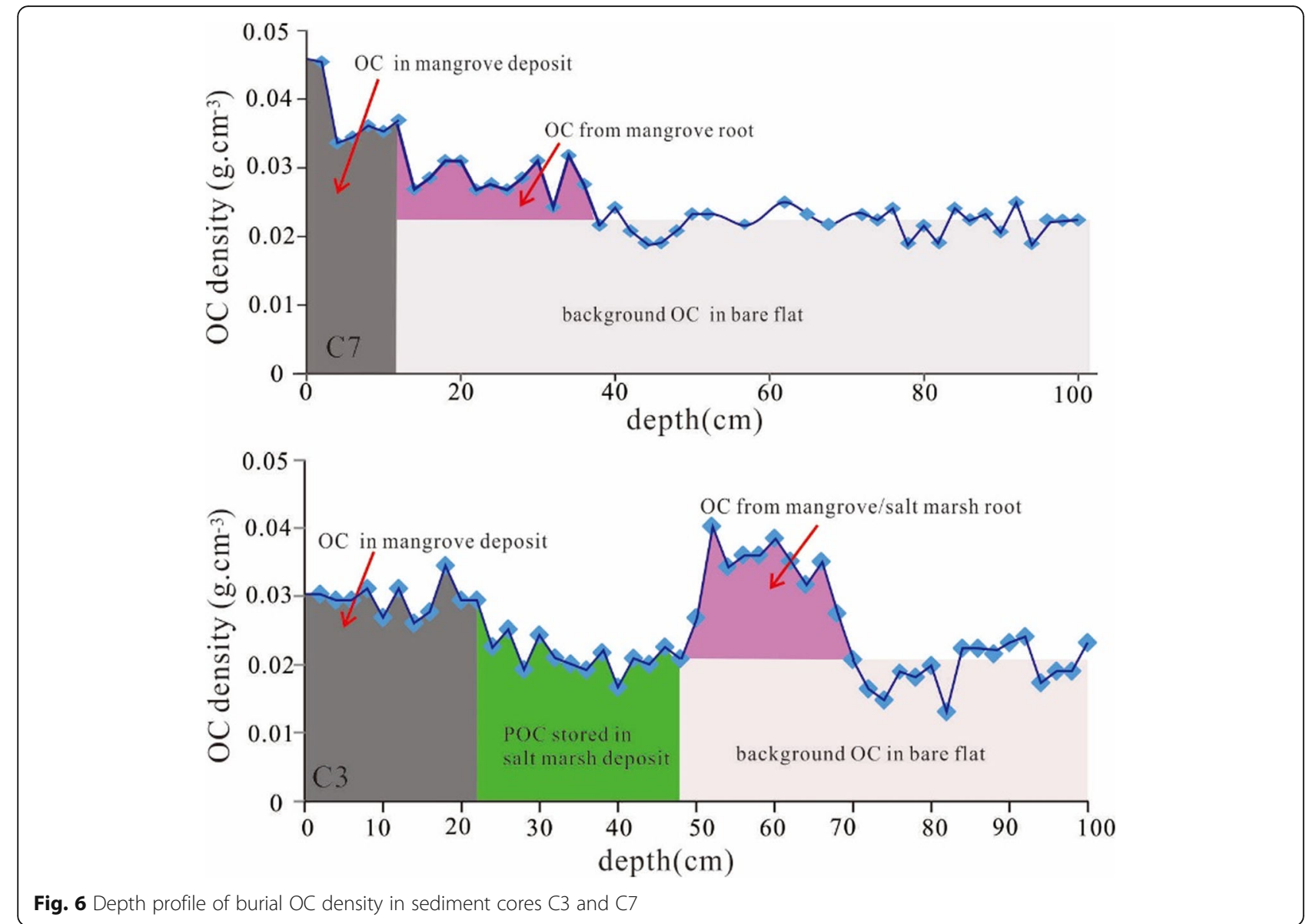

The accumulation rate of burial $\mathrm{OC}$ related to mangroves is thus estimated at $400 \mathrm{~g} \cdot \mathrm{m}^{-2} \cdot \mathrm{y}^{-1}$ (Fig. 7).

\subsection{Increase in burial OC storage in expanding mangroves} Using the estimated accumulation rate of burial $\mathrm{OC}$ in the mangrove and the time series of the mangroves of the Nanliu River estuary from 1988 to 2018, we estimated the variations of OC storage in the Nanliu River estuary during this period. As shown in Fig. 8, the increase in burial OC storage in each year was calculated by multiplying the burial $\mathrm{OC}$ accumulation rate with the mangrove area for that year. The time series of burial OC storage increment were then summed to determine the total increase in burial OC storage during this period. In this study, we used the accumulation rate of burial OC in core C3 $\left(400 \mathrm{~g} \cdot \mathrm{m}^{-2} \cdot \mathrm{y}^{-1}\right)$ as a conservative estimate. Using this, the increase in burial OC storage in the mangroves of the Nanliu River estuary over the past 30 years is estimated at approximately $35 \mathrm{Gg}$.

\section{Discussion}

In the Nanliu River estuary, the accumulation rate of burial OC in mangroves ranged from $400-500 \mathrm{~g} \cdot \mathrm{m}^{-2} \cdot \mathrm{y}^{-1}$. The highest value was observed in a young mangrove with low substrate elevation, where the OC content in sediment was higher than in the older mangrove. This can be attributed to the lower decomposition rate of organic debris in the sediment combined with a higher sediment rate and longer inundation time (Alongi et al., 2005; Nguyen et al., 2004).

The accumulation rate of burial $\mathrm{OC}$ in mangroves is generally estimated by multiplying the $\mathrm{OC}$ content with the sediment accumulation rate in the mangrove deposit layer. The OC imported to the stratigraphy beneath the

Table 1 Amount of burial OC ( per square meter)related to mangrove and salt marsh

\begin{tabular}{lllll}
\hline Position & $\begin{array}{l}\text { OC stored in mangrove } \\
\text { deposit layer }\end{array}$ & $\begin{array}{l}\text { OC imported to beneath } \\
\text { layer by mangrove root }\end{array}$ & $\begin{array}{l}\text { Total OC related } \\
\text { to mangrove }\end{array}$ & $\begin{array}{l}\text { Total OC related } \\
\text { to salt marsh }\end{array}$ \\
\hline C7 & $4436 \mathrm{~g}$ & $1554 \mathrm{~g}$ & $5990 \mathrm{~g}$ & - \\
C3 & $6498 \mathrm{~g}$ & $3120 \mathrm{~g}$ & $9618 \mathrm{~g}$ & $5655 \mathrm{~g}$ \\
\hline
\end{tabular}




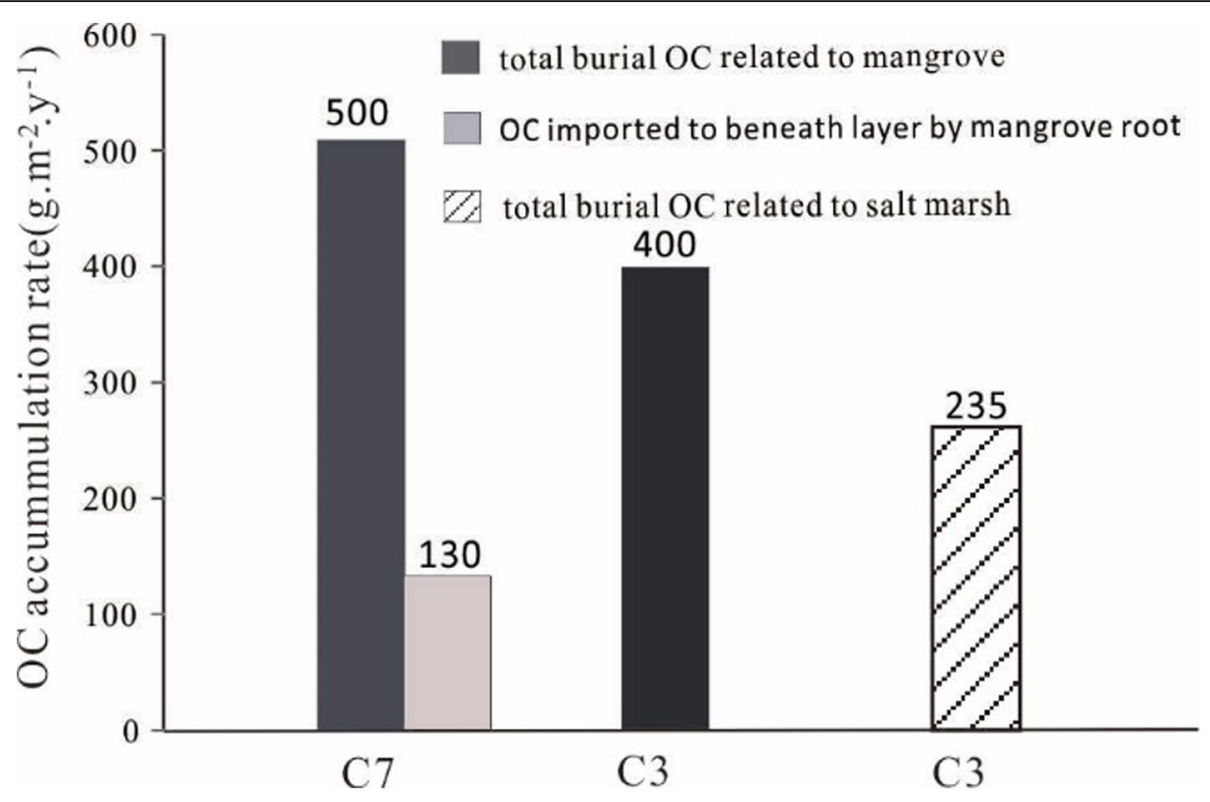

Fig. 7 Accumulation rate of burial $O C$ in mangrove and salt marsh

mangrove deposit layer may be neglected, especially when the sediment core is not long enough to cover the whole depth range of the mangrove root network. The results of this study suggest that in a young Aegiceras corniculatum forest, the accumulation rate of OC imported to the lower layer is around $130 \mathrm{~g} \cdot \mathrm{m}^{-2} \cdot \mathrm{y}^{-1}$, which was $26-32 \%$ of the total estimated OC accumulation rate. This evidence suggests that the burial OC accumulation rate in mangroves may be significantly underestimated if we neglect the OC imported to the lower layer.

According to published data gathered around the world, the relationships between the $\mathrm{OC}$ accumulation rate and the sediment accretion rate in mangroves can be well described by a linear law. This linear law is also valid for the data of this study if we neglect the OC imported to the stratigraphy beneath the mangrove deposit layer (Fig. 9). However, the total OC accumulation rate estimated in this study is significantly higher than this fitted curve, indicating that the $\mathrm{OC}$ accumulation rate is likely to be undervalued in many mangroves around the world. On the other hand, in the regions where mangroves have replaced salt marsh, the lower salt marsh deposit layer can be mistaken for mangrove deposit. Given that the $\mathrm{OC}$ accumulation rate in the salt marsh is usually lower than that in the mangrove forest, the mangrove burial $\mathrm{OC}$ accumulation rate may be undervalued.

Due to climate change, mangroves have been expanding into salt marsh areas in many regions in recent years (Comeaux et al., 2012; Saintilan et al., 2014b; Liu et al., 2017). The increase of OC burial in such mangroves is considerable. Estimating the increase in burial carbon storage in mangroves undergoing expansion is an important scientific task that will allow for a better understanding of changes in coastal carbon storage. Traditionally, changes in burial OC storage in mangroves during a certain period may be estimated using the burial OC accumulation rate, mangrove patch area, and time span. This method may be valid for stable mangroves with a
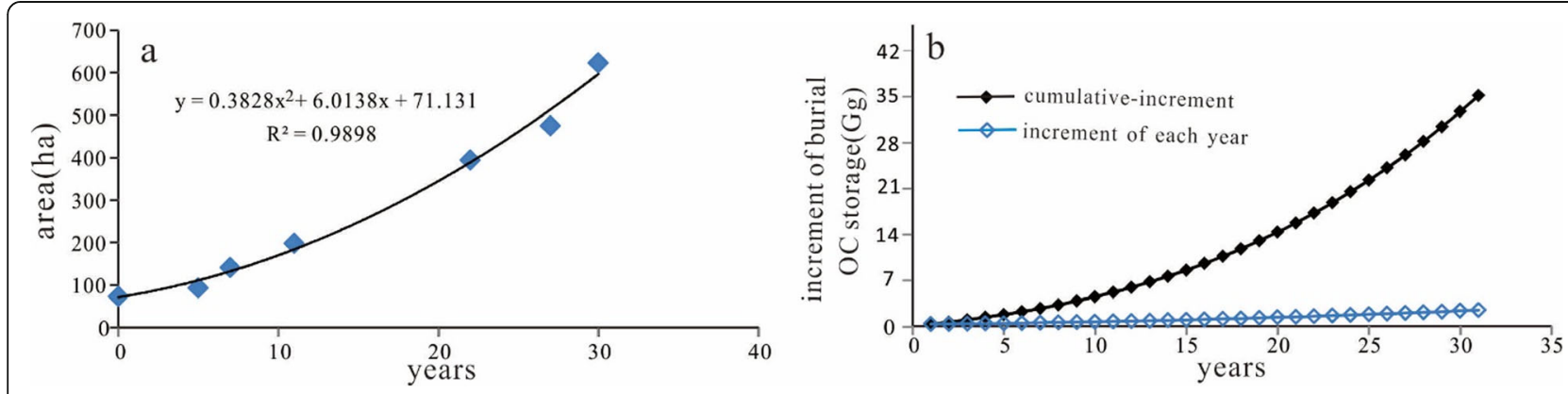

Fig. 8 a Time series of mangrove area from 1987 to 2018 in Nanliu River estuary; b increment of burial OC in Nanliu River estuary 


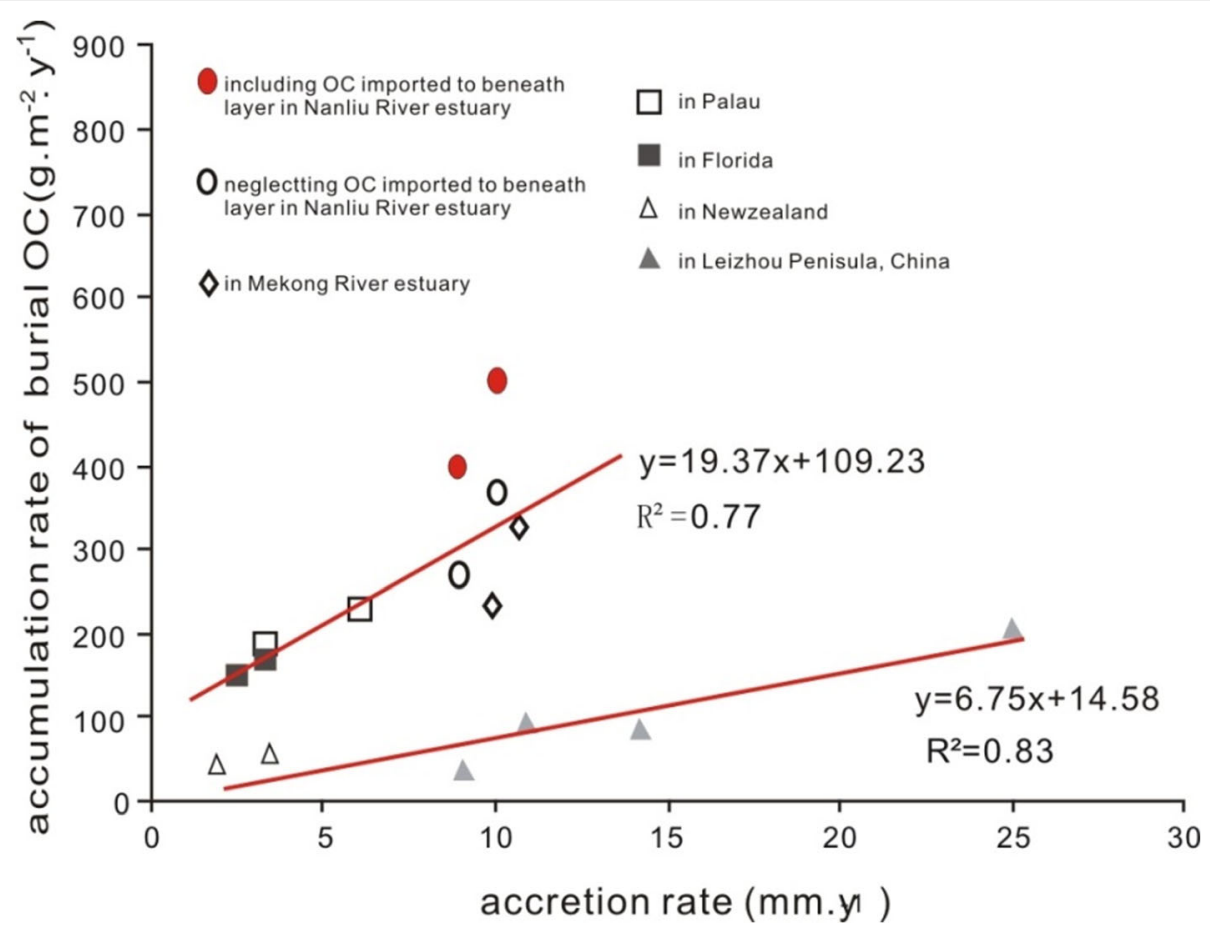

Fig. 9 The relation between accretion rate and OC accumulation rate in mangroves around the world (the data used here are revised from MacKenzie et al., 2016; Smoak et al., 2013; Pérez et al., 2017; Yang et al., 2014)

fixed area, but may not be valid for expanding mangroves. A new method must therefore be developed to solve this problem. In this study, we show an effective method for estimating the increase in the burial OC storage of mangroves undergoing expansion. Besides the accumulation rate of burial $\mathrm{OC}$, this method requires the burial $\mathrm{OC}$ accumulation rate and the time series of the mangrove area. The increment of burial OC storage in the mangrove for each year is calculated by multiplying the $\mathrm{OC}$ accumulation rate with the mangrove area of that year. Then, the total increase in burial OC during this period is estimated by summing the time series of burial OC increment. Since plenty of satellite images have been taken during past decades, we can accurately establish the time series of mangrove area in a certain region. The regional increase of OC burial in mangroves thus can be obtained easily by this method. With global warming, mangrove expansion may take place in the regions of higher latitude. According to the process and rate of mangrove expanding in a similar environment, the future change of OC burial in coastal wetlands of a certain area also can be predicted by this method. This can help us in evaluating the response of coastal carbon pool to climate change.

\section{Conclusions}

(1) Based on the division of sedimentary facies from two sediment cores and estimates of mangrove age determined by historical satellite image analysis, the burial
OC accumulation rates of mangroves in the Nanliu River estuary were estimated. The results show that the OC accumulation rate in these mangroves is approximately $400-500 \mathrm{~g} \cdot \mathrm{m}^{-2} \cdot \mathrm{y}^{-1}$, of which the OC imported to the lower layer of the mangrove roots is approximately $130 \mathrm{~g} \cdot \mathrm{m}^{-2} \cdot \mathrm{y}^{-1}$.

(2) Globally, reported burial OC accumulation rates in mangroves are well linearly correlated to the accretion rate. In this study, however, the total $\mathrm{OC}$ accumulation rates are significantly higher than the corresponding value on the fitted curve, indicating that the burial OC accumulation rates may be undervalued in these mangroves because the $\mathrm{OC}$ imported to the lower layer by mangrove roots has been neglected.

(3) Using an integrated method, we utilised the burial OC accumulation rate and the time series of the mangrove area from 1988 to 2018 to estimate the increase in burial OC storage in mangroves. By our estimate, burial $\mathrm{OC}$ storage by mangroves amounts to more than $35 \mathrm{Gg}$ over this 30 year period.

\section{Acknowledgements}

We would like to thank Mr. Lianghao Pan, Mr. Yancheng Tao, and Mr. Wenai Liu for sediment samples collecting.

\section{Authors' contributions}

$T L$ participated in the data analysis and research idea design and completed the main work of the paper. SFL conceived of the study and participated in its design and coordination. BW participated in the data analysis and drafted the manuscript. HPX participated in the sample analysis and drafted the 
manuscript. $\mathrm{HZ}$ participated in the sample analysis and drafted the manuscript. All authors read and approved the final manuscript.

\section{Funding}

This work was supported by the National Nature Science Foundation of China-Shandong Province Joint Fund for Marine Science Research Centers (U1606401), National Programme on Global Change and Air-Sea Interaction (GASI-GEOGE-03), and Taishan Scholar Program of Shandong.

\section{Availability of data and materials}

The dataset supporting the conclusions of this article can be found in the supplementary files.

\section{Competing interests}

The authors declare that they have no competing interests.

\section{Author details}

${ }^{1}$ School of Marine Sciences, Guangxi University, Nanning 530004, China. ${ }^{2}$ Key Laboratory of Environment Change and Resources Use in Beibu Gulf, Ministry of Education, Guangxi Teachers Education University, Nanning 530004, China. ${ }^{3}$ Key Laboratory of Marine Geology and Metallogeny, First Institute of Oceanography, Ministry of Natural Resources, Qingdao 266061, China. ${ }^{4}$ Laboratory for Marine Geology, Qingdao National Laboratory for Marine Science and Technology, Qingdao 266061, China.

Received: 22 June 2020 Accepted: 3 November 2020

Published online: 16 November 2020

\section{References}

Alongi DM (2014) Carbon Cycling and Storage in Mangrove Forests. Annu Rev Mar Sci 6:195-219

Alongi DM, Pfitzner J, Trott LA, Tirendi F, Dixon P, Klumpp DW (2005) Rapid sediment accumulation and microbial mineralization in forests of the mangrove kandelia candel in the jiulongjiang estuary, china. Estuar Coast Shelf Sci 63(4):605-618

Cavanaugh KC, Kellner JR, Forde AJ et al (2014) Poleward expansion of mangroves is a threshold response to decreased frequency of extreme cold events. Proceedings of the National Academy of Sciences 111:723-727

Comeaux RS, Allison MA, Bianchi TS (2012) Mangrove expansion in the Gulf of Mexico with climate change: Implications for wetland health and resistance to rising sea levels. Estuarine, Coastal and Shelf Science 96:81-95

Donato DC, Kauffman JB, Murdiyarso D et al (2011) Mangroves among the most carbon-rich forests in the tropics. Nat Geosci 4:293-297

Ezcurra P, Ezcurra E, Garcillán PP, Costa MT, Aburto-Oropeza O (2016) Coastal landforms and accumulation of mangrove peat increase carbon sequestration and storage. Proceedings of the National Academy of Sciences 113:4404-4409

Giri C, Ochieng E, Tieszen LL et al (2011) Status and distribution of mangrove forests of the world using earth observation satellite data. Glob Ecol Biogeogr 20:154-159

Jardine SL, Siikamäki JV (2014) A global predictive model of carbon in mangrove soils. Environ Res Lett 9:104013

Liu T, Tao Y, Liu Y (2017) Mangrove swamp expansion controlled by climate since 1988: a case study in the Nanliu River Estuary, Guangxi, Southwest China. Acta Oceanol Sin 36:11-17

Mackenzie RA, Foulk PB, Klump JV, Weckerly K, Purbospito J, Murdiyarso D (2016) Sedimentation and belowground carbon accumulation rates in mangrove forests that differ in diversity and land use: a tale of two mangroves. Wetl Ecol Manag 24(2):245-261

Mcleod, E., Chmura, G.L., Bouillon, S., et al., Schlesinger, W.H., Silliman, B.R., 2011. A blueprint for blue carbon: toward an improved understanding of the role of vegetated coastal habitats in sequestering $\mathrm{CO}_{2}$. Front Ecol Environ 9, 552-560

Nguyen HT, Yoneda R, Ninomiya I et al (2004) The effects of stand-age and inundation on carbon accumulation in mangrove plantation soil in Namdinh, Northern Vietnam. Tropics 14:21-37

Pérez A, Machado W, Gutierrez D et al (2017) Changes in organic carbon accumulation driven by mangrove expansion and deforestation in a New Zealand estuary. Estuarine, Coastal and Shelf Science 192:108-116
Saintilan N, Wilson NC, Rogers K, Rajkaran A, Krauss KW (2014a) Mangrove expansion and salt marsh decline at mangrove poleward limits. Global Change Biol 20:147-157

Saintilan N, Wilson NC, Rogers K, Rajkaran A, Krauss KW (2014b) Mangrove expansion and salt marsh decline at mangrove poleward limits. Global Change Biol 20:147-157

Smoak JM, Breithaupt JL, Smith TJ, Sanders CJ (2013) Sediment accretion and organic carbon burial relative to sea-level rise and storm events in two mangrove forests in everglades national park. Catena 104(2):58-66

Yang J, Gao J, Liu B, Zhang W (2014) Sediment deposits and organic carbon sequestration along mangrove coasts of the Leizhou Peninsula, southern China. Estuarine, Coastal and Shelf Science 136:3-10

\section{Publisher's Note}

Springer Nature remains neutral with regard to jurisdictional claims in published maps and institutional affiliations.

\section{Submit your manuscript to a SpringerOpen ${ }^{\circ}$ journal and benefit from:}

- Convenient online submission

- Rigorous peer review

- Open access: articles freely available online

- High visibility within the field

- Retaining the copyright to your article

Submit your next manuscript at $\boldsymbol{\nabla}$ springeropen.com 